\title{
An ICF Perspective on Impact of Environmental Barriers on Community Participation in Stroke Patients: A Qualitative Approach
}

\author{
Isha S Akulwar*1 and Nivedita C Shahane ${ }^{2}$ \\ ${ }^{1}$ M.P.Th. in Neurosciences Physiotherapy, Associate Professor, K. J. Somaiya College of Physiotherapy, Mumbai, India \\ ${ }^{2}$ Nivedita C. Shahane, M. P. Th. in Cardiovascular \& Respiratory Sciences, India
}

*Corresponding author: Isha S Akulwar, M.P.Th.Neurosciences Physiotherapy, Associate Professor, K.J. Somaiya College of Physiotherapy, Mumbai, India, Email: drishasa@yahoo.co.in.

Received Date: August 02, 2019

Published Date: August 07, 2019

\section{Abstract}

Objective: To explore the environmental factors acting as barriers to community participation from the perspective of ICF in individuals with stroke.

Design: Observational.

Setting: Physiotherapy department of a tertiary care center.

Participants: 50 stroke patients with hemiplegia, ambulatory (with/without assistive devices) and community-dwelling voluntarily participated. Patients with severe cognitive, visual, perceptual and communication deficits were excluded. Convenience sampling was used.

Main outcome measure: A questionnaire was designed based on the domains of International Classification of Functioning and Disability; and included elements of physical and social environments. This was administered through a semi-structured interview.

Result: Among the various factors identified, mobility barriers community (e.g., uneven sidewalks, unavailability of lifts) and at home (e.g., stairs or doors) have been implicated to limit community participation by majority of subjects ( $97 \%$ \& $87 \%$ ) followed by lack of accessibility of roads (95\%), lack of accessibility of restrooms (55\%) and lack of accessibility of transport (45\%). Lack of services, systems and policies was perceived as a barrier and inappropriate attitude and lack of support of family and friends by $25 \%$ and $20 \%$ subjects respectively.

Conclusion: Environmental factors are crucial determinants of community participation in stroke patients. Along with physical environmental factors, social and attitudinal aspects of environment also have an impact on community participation by stroke patients.

Clinical Implications: Knowledge of these findings will assist rehabilitation of stroke patients by overcoming barriers and enhancing facilitators through environmental modification in community for easy accessibility, training in community/in a simulated environment and policy changes e.g. changes in regulations, insurance, etc.

Keywords: Environmental barriers, Community participation; Stroke

\section{Introduction}

Stroke is the leading cause of disability in adults [1]. More than half of stroke survivors are discharged to their homes, with more or less severe, persistent neurological symptoms and impairments in terms of functional limitations and disability [2]. According to the WHO (2009), there are 6,398,000 DALYs (Disability adjusted life year) lost due to stroke in India. In developing countries like India, people with stroke after receiving medical treatment from the acute care setup are directly discharged to their homes. Relatively few rehabilitation centres exists and due to lack of access to facilities in the community, patients with stroke find it difficult to continue with therapy services. This in turn affects the outcome of stroke survivors. Survivors of stroke rate the ability to "get out and about" and into the community as "essential" or "very important" [3]. Independent ambulation within the community is an important goal for the patient with stroke [4]. Community ambulation refers to the ability to walk with or without gait aid to destinations important for participation in community life [5]. This includes independent mobility outside home which includes the ability to confidently negotiate uneven terrain, private venues, shopping centres and other public venues. People with stroke are affected in their walking ability. This affects their ability to participate in social life for functioning. 
The International Classification of Functioning and Disability (2001) is an amalgam of the medical and social models and brings into focus the interaction of the body's structure and function, activities, and participation in life situations (Figure 1). The diagram identifies the three levels of human functioning classified by ICF: functioning at the level of body or body part, the whole person, and the whole person in a social context. Disability therefore involves dysfunctioning at one or more of these same levels: impairments, activity limitations and participation restrictions. In ICF disability and functioning are viewed as outcomes of interactions between health conditions (diseases, disorders and injuries) and contextual factors. The contextual factors representing the individual's life and living are divided into environmental and personal domains [6,7] (Figure 1).

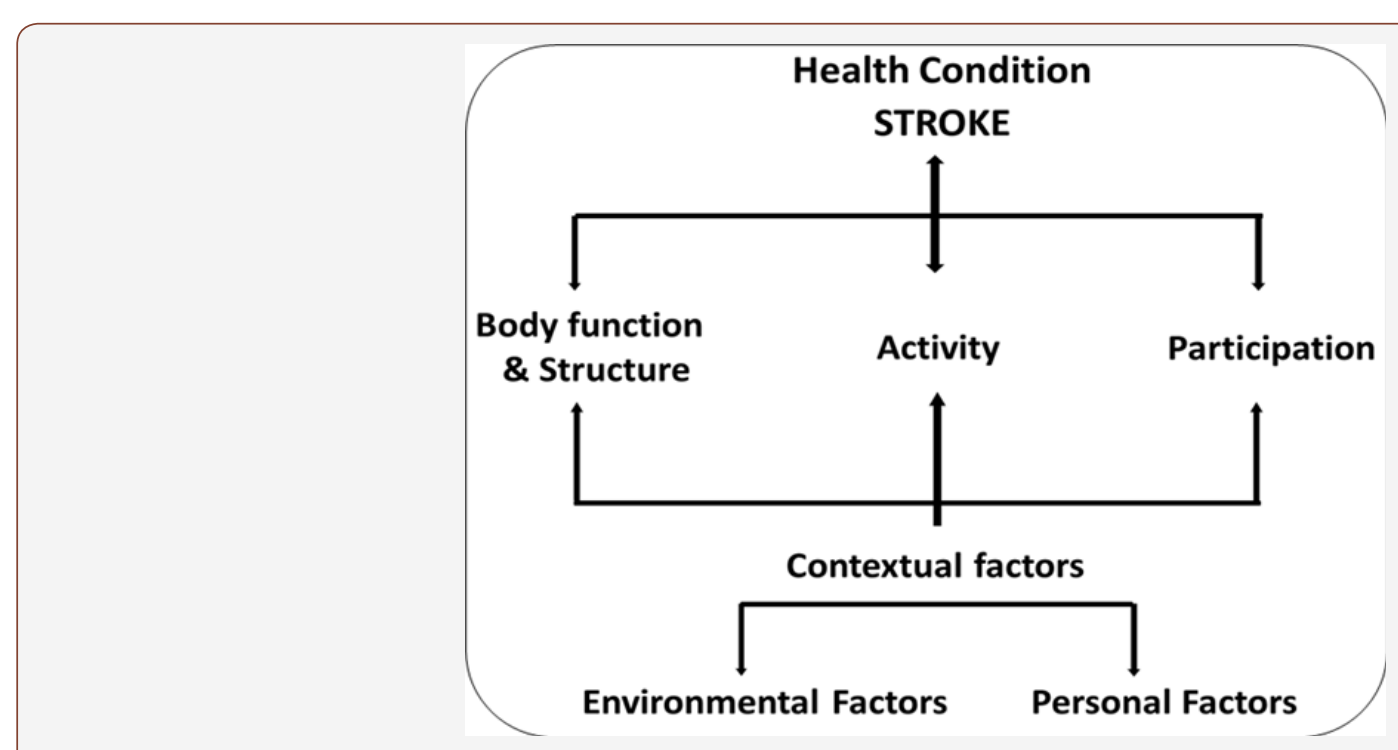

Figure 1: Schematic representation of the ICF (WHO, 2001)

Environmental factors are hypothesized to be crucial determinants of people's participation in daily activities [8]. Interaction with environmental factors is an essential aspect of the scientific understanding of the phenomena included under the umbrella terms 'functioning and disability' [7]. The environmental domain of the ICF comprises the physical environment and nonphysical environment such as social and attitudinal factors, which comprised the lived environment. This includes Products \& Technology; Natural \& human-made changes; Support \& Relationships; Attitudes; and Services, systems \& Policies. The impact of the physical environment is highly relevant when assessing community ambulation. The ICF enumerates the impact of the physical environment on the activity of walking with subsections that include variable distances, different terrains, obstacles and different locations [7]. As the physical environment include various safety hazards, access problems and home or workplace design difficulties, they can act as barriers for community participation. The social and attitudinal aspects of the environmental domain include family and friends, services such as non-profit organizations, and government agencies and systems such as rules and regulations within communities and facilities. The attitude and support of peers and family, the provision of assistive devices or modification to the work place environment to facilitate a return to work may have as great an impact as any impairment on an individual's achievement of personal goals and the attainment of a reasonable quality of life $[9,10]$. All of these factors are external to the individual. Both the community participation \& environmental factors are context -specific \& culturally sensitive. There is a lack of published data in Indian context.
Disability is a complex phenomenon that is both a problem at the level of a person's body, and a complex and primarily social phenomena. ICF is based on biopsychosocial model of disability and provides, by this synthesis, a coherent view of different perspectives of health: biological, individual and social. We hypothesized that ICF will be useful in identifying the effect of the physical and social environment on the disadvantages that the stroke-survivors experience in their lives.

In order to effectively retrain stroke patients to ambulate in their community, health professionals must understand the impact of local environment and use this knowledge to assist a client's rehabilitation programme ${ }^{5}$. It is necessary for health professionals to acknowledge many physical and non physical factors that can facilitate or limit an individual's participation in society. One should focus on overcoming barriers and enhancing facilitators through modifications in environment [8]. Thus, this study was undertaken to identify the environmental factors perceived by the stroke patients as barriers to community participation.

\section{Methodology}

A questionnaire was designed based on the domains of ICF and included elements of physical and social environments. The questionnaire was administered through a semi-structured interview. Stroke patients with hemiplegic involvement, duration of onset $\geq 3$ months, ambulatory (with/ without assistive devices), mini mental scale score of $\geq 24$ and community-dwelling were selected. The study criterion of 'community-dwelling' was appropriately chosen to ensure that the stroke subjects participate in social activities and are exposed to environmental barriers. 
(Figures 2-4) Stroke patients with severe cognitive, visual, perceptual and communication deficits were excluded. 50 stroke patients attending a tertiary care hospital for Physiotherapy voluntarily participated. Informed consent was obtained from all the participants. The procedures followed protocol and accord with the ethical standards of the institutional review board. Data analysis was done using descriptive statistics (Figures 2-4).

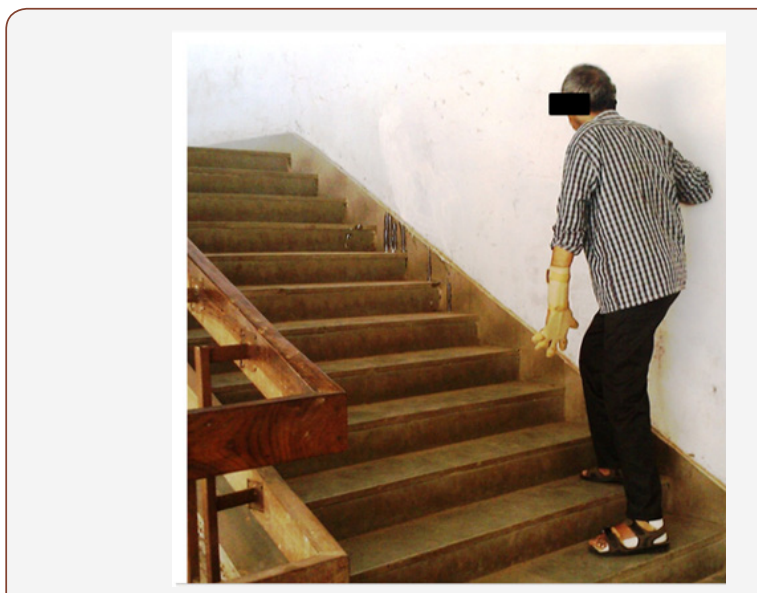

Figure 2: An individual with stroke and left hemiplegia finds unavailability of rails on right side while climbing stairs as a barrier

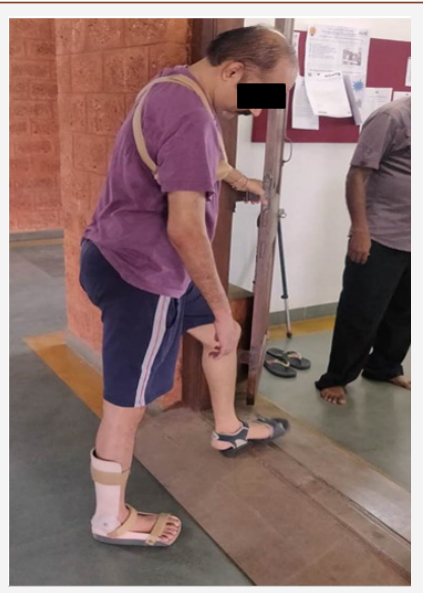

Figure 3: A raised threshold at the door is perceived as a barrier by an individual with stroke

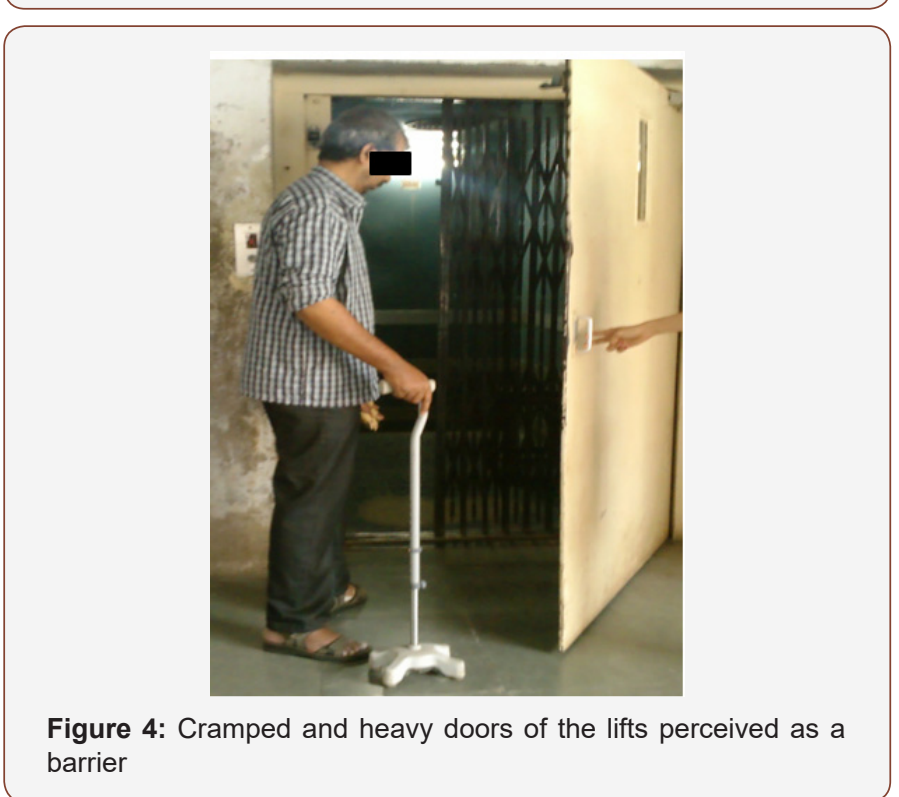

\section{Results and Discussion}

Table 1: Descriptive data of participants

\begin{tabular}{|c|c|c|}
\hline \multicolumn{2}{|c|}{ Age (in years) } & $51.4 \pm 9.13($ mean \pm SD) \\
\hline Duration of Stroke (in months) & $15.23 \pm 21.34$ (mean \pm SD) \\
\hline \multicolumn{2}{|c|}{ Customary Mode of Mobility } & $\%$ of individuals \\
\hline \multirow{2}{*}{ Use of Assistive Device } & At home & 13 \\
\cline { 2 - 3 } & In community & 47 \\
\hline \multirow{2}{*}{ Manual Assistance } & At home & 12 \\
\cline { 2 - 3 } & In community & 77 \\
\hline \multirow{2}{*}{$\begin{array}{c}\text { Employment Status } \\
\text { (after the stroke) }\end{array}$} & Unemployed & Self-employed \\
\cline { 2 - 3 } & Leave Home Less often after Stroke \\
\hline \multicolumn{2}{|c|}{$\begin{array}{c}\text { Use of Mobility Device does Influence } \\
\text { (Helps) Community Participation }\end{array}$} \\
\hline
\end{tabular}

Table 2: Features of the Physical Factors reported as Barriers at Home and in the Community

\begin{tabular}{|c|c|}
\hline Physical Factors & Feature/S Reported as Barrier \\
\hline Stairs & $\begin{array}{l}\text { Unavailability of rails on one/both the sides; } \\
\text { narrow width; more number; inappropriate height }\end{array}$ \\
\hline Lifts & $\begin{array}{l}\text { Unavailability; cramped and manual doors; high } \\
\text { placement of control buttons in automatic lifts }\end{array}$ \\
\hline Doors & Narrow doorways, raised threshold \\
\hline Floor & Uneven, slippery \\
\hline Roads & $\begin{array}{l}\text { Potholes, uneven pathways; crowded; } \\
\text { unavailability of/uneven sidewalks; unavailability } \\
\text { of crossing access; narrow turns at curb cuts }\end{array}$ \\
\hline Public transport & Inaccessibility \\
\hline Ramps & Unavailability \\
\hline Restrooms & $\begin{array}{l}\text { Unavailability of rails inside; inadequate space to } \\
\text { move; slippery floors; narrow entrance }\end{array}$ \\
\hline \multicolumn{2}{|l|}{ Seating } \\
\hline arrangements & Unavailability of appropriate chairs \\
\hline
\end{tabular}

50 stroke patients with a mean $( \pm$ SD) age of 51.4 years \pm 9.13 and mean $( \pm$ SD) duration since stroke $15.23 \pm 21.34$ months participated in the study (Table 1). $47 \%$ of patients required assistive device for 'community' ambulation and $13 \%$ required assistive device while $12 \%$ required help 'at home' for ambulation. Among the various environmental factors identified (Table 2), mobility barriers at home and surroundings were reported by $87 \%$ of stroke patients and were implicated for limiting their community participation. (Figure 5) In home and surroundings, stairs (number, unavailability of rails, height), floor (uneven, slippery), lifts (unavailability) and doors (raised threshold) were perceived as barriers in $92.17 \%, 43.25 \%, 35.29 \%$ and $23.52 \%$ of stroke patients respectively. Mobility barriers in community were reported in $97 \%$ of stroke patients and were implicated for limiting community participation (Figure 6). In community, stairs (number, unavailability of rails, height), lifts (unavailability), floors (uneven, slippery) and ramps (unavailability) were perceived as barriers in $88.41 \%, 69.36 \%, 26.52 \%$ and $10.15 \%$ of stroke patients respectively. Lack of restroom accessibility was perceived as a barrier in $52 \%$ of stroke patients and unavailability of rails, inadequate space to move, floors (slippery) and entrance (narrow) 
were implicated in $91.96 \%, 50.15 \%, 59.52 \%$ and $41.16 \%$ of stroke patients respectively. Lack of accessibility of roads was perceived as a barrier in $97 \%$ of stroke patients in which the factors such as pathways (uneven), crowd, sidewalks and crossing were perceived as barriers in $93.47 \%, 76.42 \%, 56.90 \%$, and $55.31 \%$ of stroke patients respectively. Lack of public transport was perceived as a barrier by $49.5 \%$ of stroke patients. In natural environmental features limiting community participation, $70 \%$ perceived rain; $40 \%$ perceived light (darkness at night, clouds) while $18.12 \%$ perceived noise as a barrier. (Table 1\&2) (Figure 5-7).

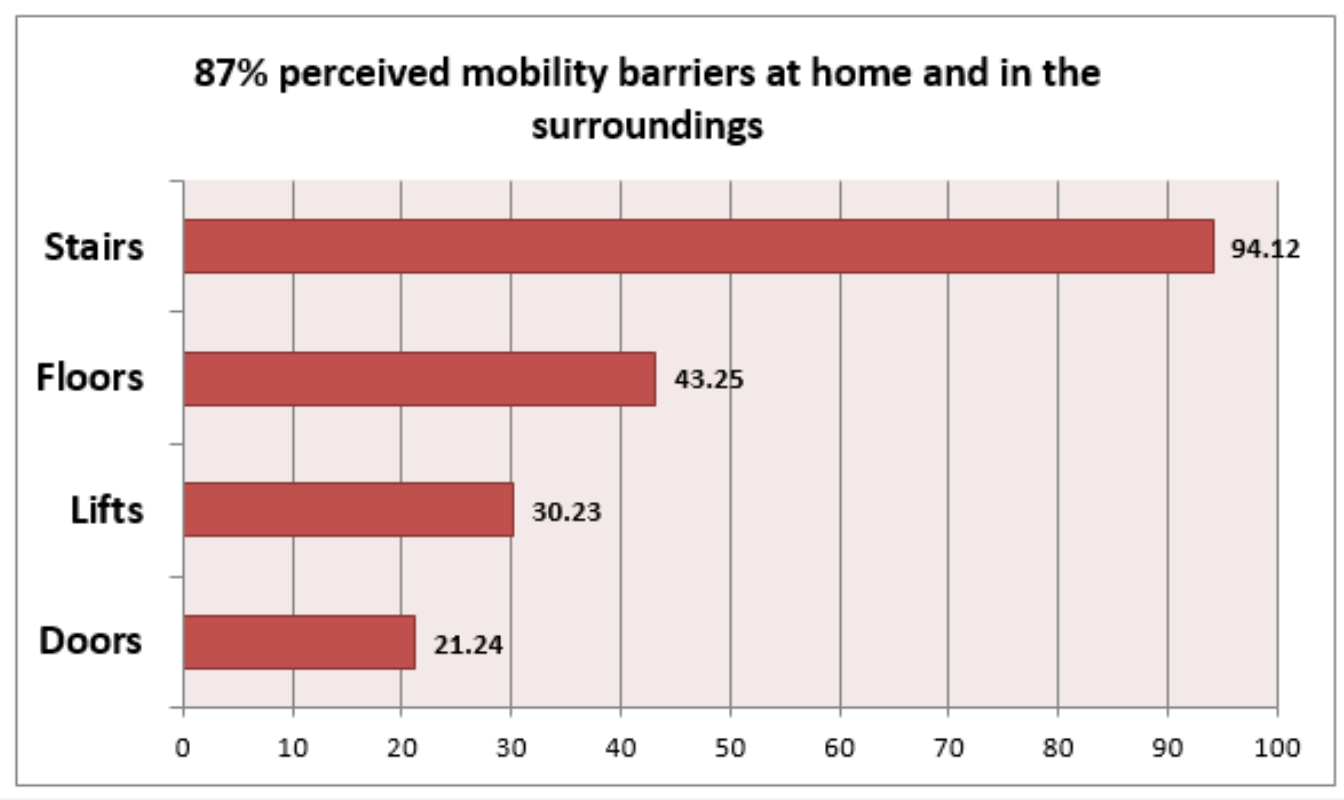

Figure 5: Mobility barriers at home and in surroundings

\section{$97 \%$ perceived mobility barriers in the community}

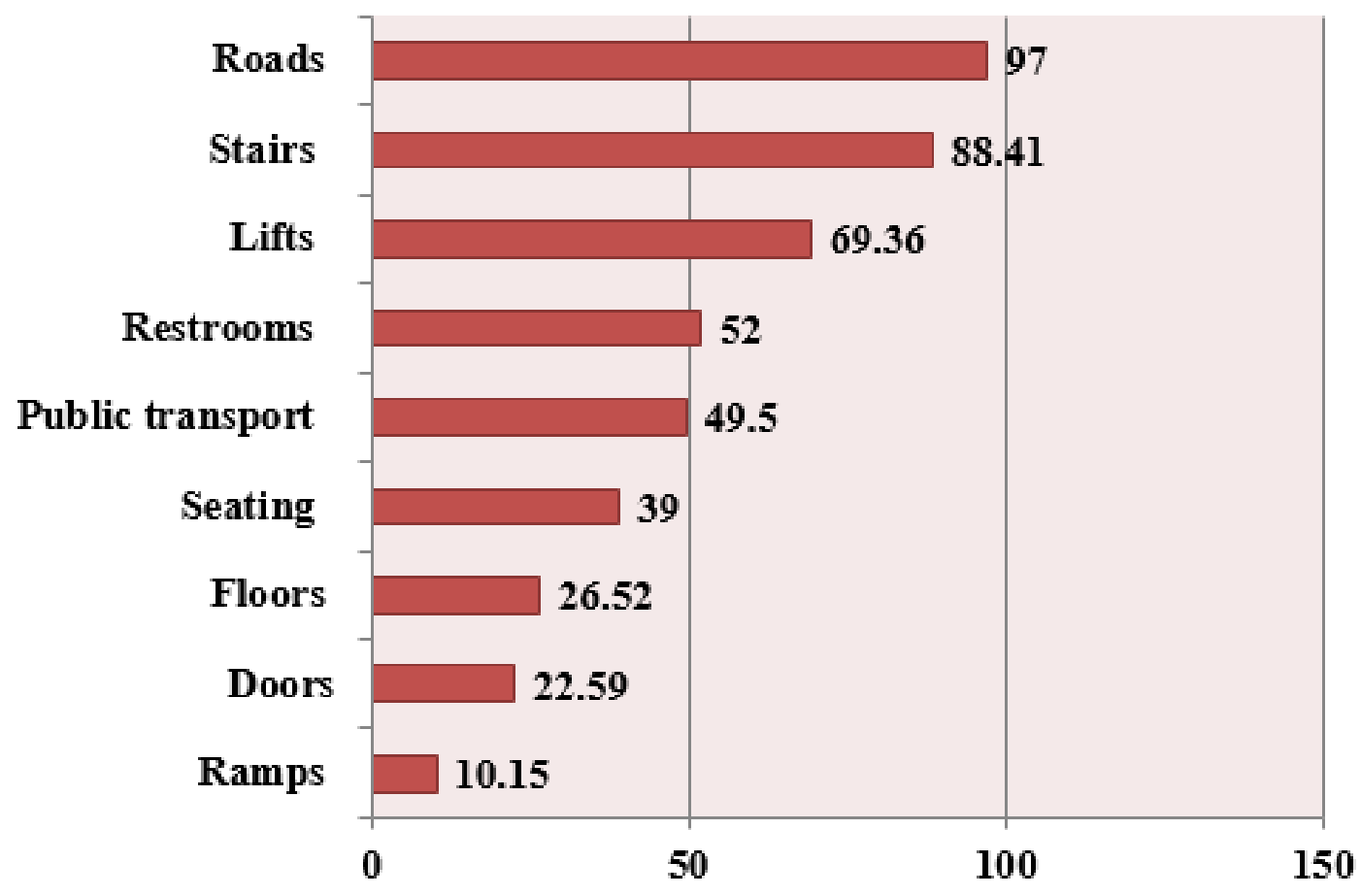

Figure 6: Mobility barriers in the community 
$46 \%$ reported lack of 'Services, systems \& Policies' limit their community participation

Services, systems and policies programs

Attitude of Personal attendants

Attitude of community members

Support and relationships

Attitude of friends, colleagues, neighbors

Attitude of immediate family members

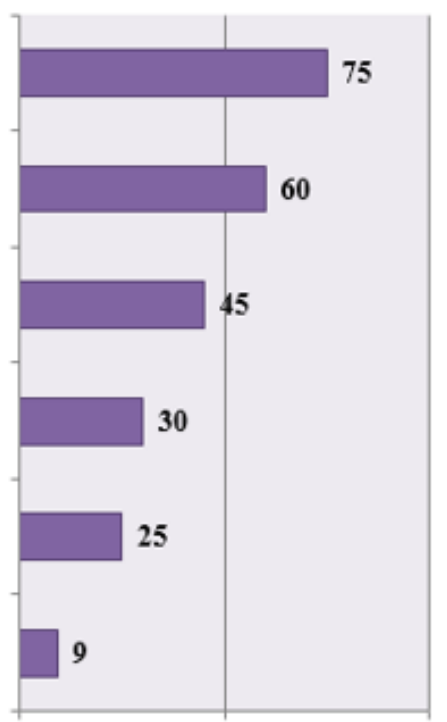

50

Figure 7: Social features of environment perceived as barriers

In non-physical factors, attitude of immediate family members; attitude of friends, colleagues, neighbors; attitude of community members; attitude of personal attendants was perceived as a barrier in community participation by $9 \%, 25 \%, 45 \%$ and $60 \%$ of stroke patients respectively. Lack of support from family was perceived as a barrier in community participation by $30 \%$ of stroke patients and services, systems and policies were perceived as a barrier in $75 \%$ of stroke patients. (Figure 8)

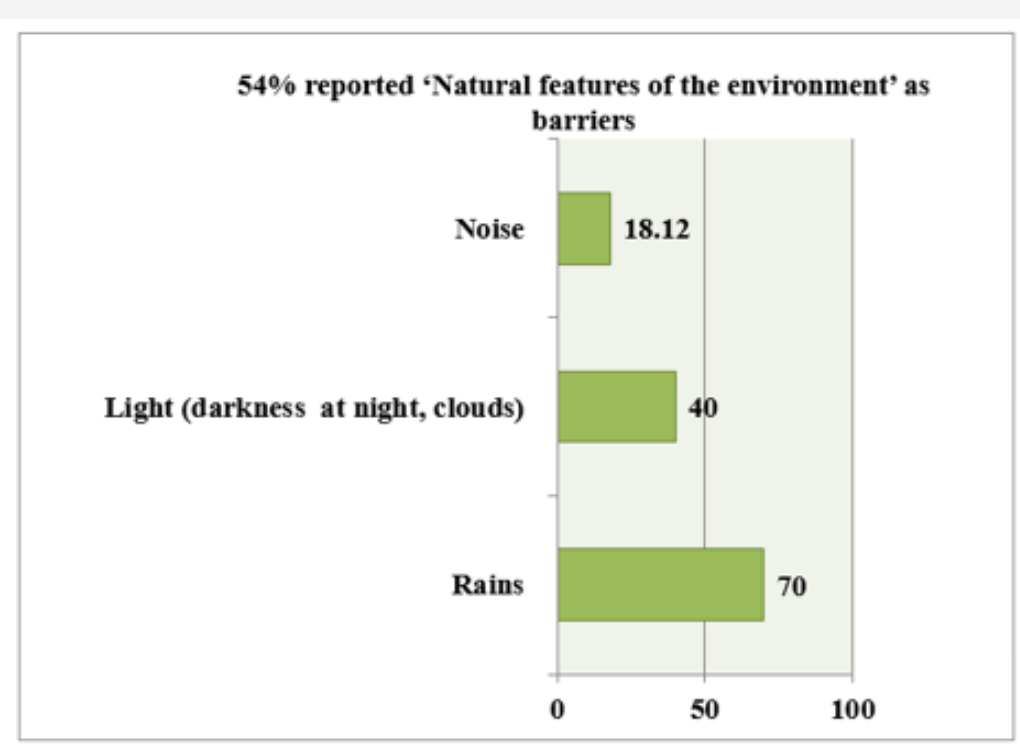

Figure 8: Natural features of environment perceived as barriers

Similar findings have been reported in previous studies with significantly lower rate of participation with variety of environmental barriers such as architectural, discrimination, social attitudes, cost of services or programs, inaccessible facilities [1115]. Few researchers have attempted to explore the factors acting as barriers and facilitators in environmental as well as personal context in stroke patient's ambulatory activities in community [11-13]. However, all these studies have been done abroad and have emphasized on personal factors of stroke patients. To the best of our knowledge, this is the first Indian study in which an attempt was made to explore the environmental barriers to community participation in stroke patients. We ensured that the questionnaire designed includes all the factors in the local environment and is applicable to community participation for a patient with stroke. Also, an important aspect of the present study is that the environmental barriers were identified from the patient's perspective. Individual response to disease course and the patient attitude towards community participation are important 
considerations in a clinician's decision-making process. During stroke rehabilitation, a consideration of the environmental barriers likely to be encountered by a patient in the community may be essential for determining the likelihood of successful community ambulation [16]. In the past, a therapist-centered approach was considered to be important in guiding the various therapeutic activities facilitating normal movement. However, the treatment paradigm in stroke rehabilitation has shifted to a more patientcentered approach that involves establishing a problem solving strategy whereby patients are actively involved in the decision making process. Such a concept has been shown to be beneficial in improving physical and cognitive function [17], demonstrating how this approach could have a direct impact on community ambulation ability.

Another highlight of this study is the use of ICF for designing the questionnaire. One of the important applications of ICF is for environmental assessment for universal design, implementation of mandated accessibility, identification of environmental facilitators and barriers, and changes to social policy: How can we make the social and built environment more accessible for all persons, those with and those without disabilities? Can we assess and measure improvement? ICF can provide the framework for comprehensive and coherent disability-related social policy such as devising eligibility criteria for disability pensions, developing regulations for access to assistive technology, or mandating housing or transportation policy that accommodates individuals with mobility, sensory or intellectual disability; and anti-discrimination legislation, etc.

\section{Conclusion}

Environmental factors are crucial determinants of community participation in stroke patients. Apart from physical environmental factors, social and attitudinal aspects of environment also have an impact on community participation by stroke patients. With this information in hand, it will then be more practical to develop and implement guidelines for universal design and other environmental regulations that extend the functioning levels of persons with disabilities across the range of life activities.

\section{Limitations}

This study has several limitations which could have affected the results of the study. Impact of confounding factors such as physical impairments and personal factors on community participation was not considered in the study. Individuals with communication or cognition problems were excluded from the study; therefore, the sample may only represent a group of individuals with no significant communication or cognition problems post-stroke while the excluded group might have different experiences. Due to relatively small sample, findings of this study cannot be generalized to other stroke survivors from different socioeconomic strata and other geographical area.

\section{Implications for rehabilitation: (Figure 9)}

In order to retrain the individual with stroke to his/her previous activities and community participation, knowledge of environmental barriers is very important. Findings of this study have important clinical implications and will assist in rehabilitation of stroke patients by overcoming the barriers and enhancing the facilitators through environmental modification for easy accessibility; training stroke patients in the community or in a stimulated environment; and policy changes in regulations, insurance, etc. Considering the social discrimination towards individuals with stroke, there is a need for growing public awareness and social inclusion. There is also an increased recognition among social planners and service agencies that reductions in the incidence and severity of disability in a population can be brought about both by enhancing the functional capacity of the person and by improving performance by modifying features of the social and physical environment. This study has analyzed the impact of these features and has provided the necessary preliminary information.

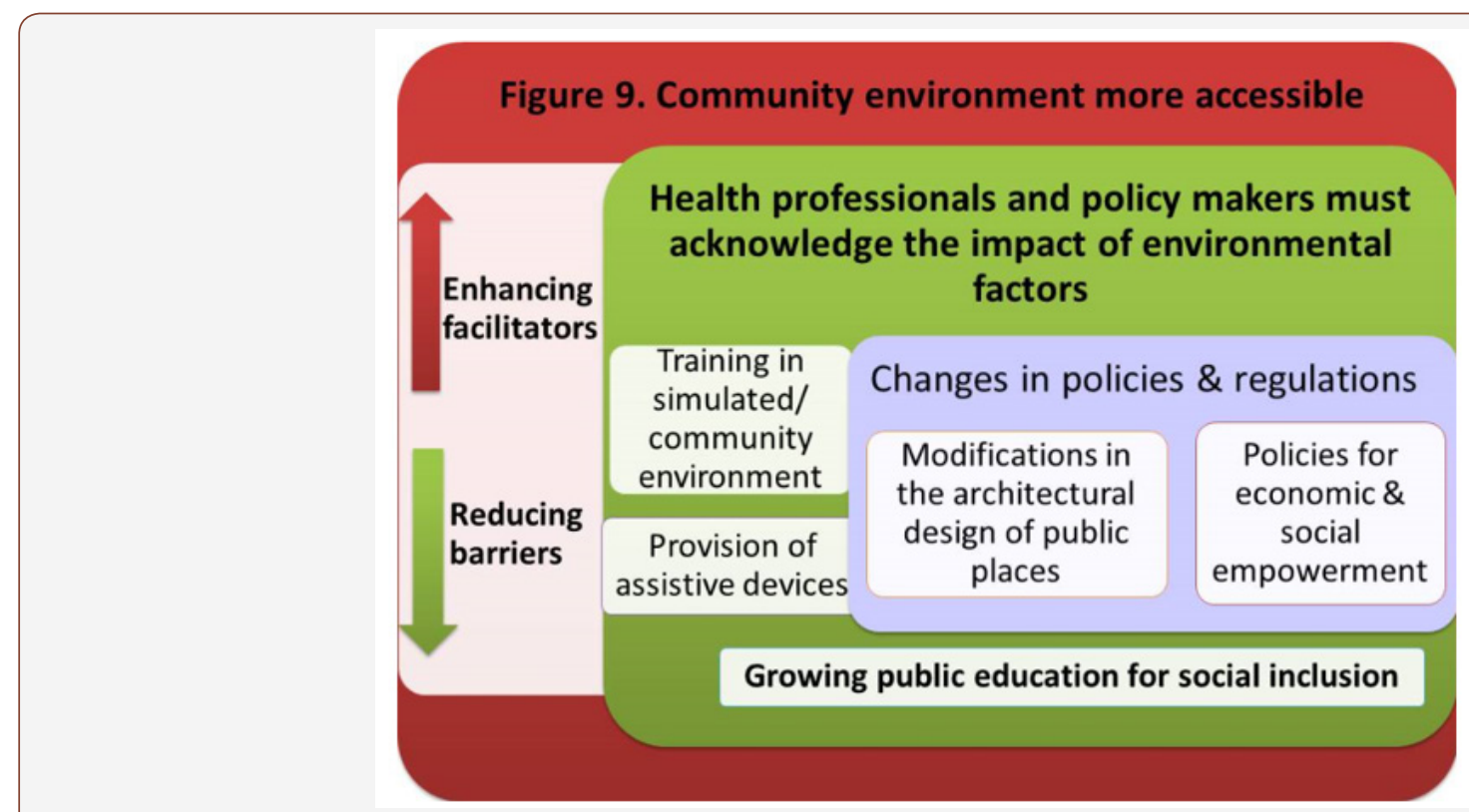

Figure 9: Community environment more accessible 


\section{Implications for further research: (Figure 10)}

Findings of this study indicate a need for similar studies to be conducted on a larger scale in stroke patients and in people with different disability conditions. Results of this study provide important data for developing needs assessment tools at the social level for individuals with stroke. There is a need to develop objective instruments for assessment of environmental factors in terms of their level of facilitation or barrier-creation. Such tools may need to be designed considering their applicability to the country's local environment. Also, community participation should be one of the outcome measures of stroke rehabilitation studies.

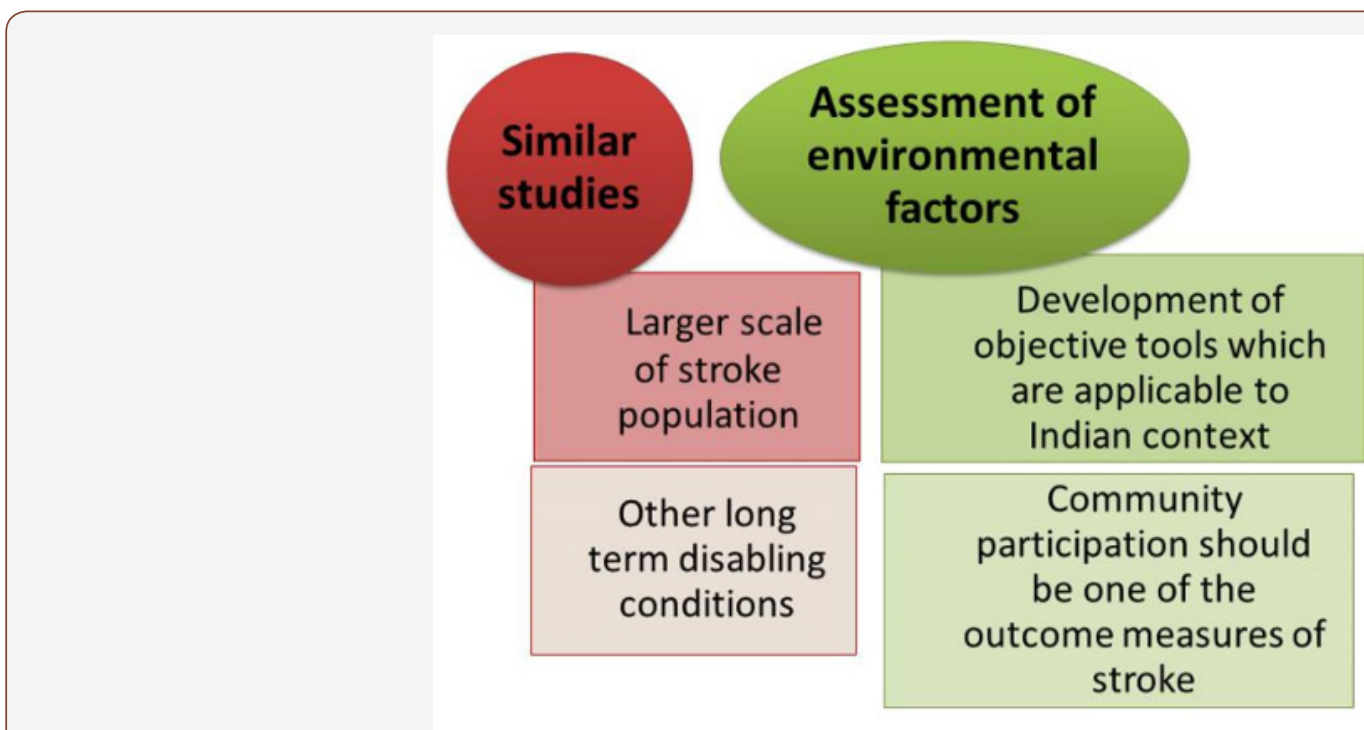

Figure 10: Implications for further research

\section{Acknowledgement}

I would like to thank study participants and Principal of K. J. Somaiya college of Physiotherapy, Mumbai for their valuable contribution.

\section{Conflict of Interest}

None.

\section{References}

1. Sridharan SE, Unnikrishnan JP, Sukumaran S, Sylaja PN, Nayak SD, et al. (2009) Incidence, Types, Risk factors and outcome of stroke in a developing country: The Trivandrum stroke Registry. Stroke 2009 40(4): 1212-1218.

2. Andersen HE, Schultz-Larsen K, Kreiner S, Forchhammer BH, Eriksen $\mathrm{K}$, et al. (2000) Can readmission after stroke be prevented? Results of randomized clinical study: A post discharge follow up service for stroke survivors. Stroke 31: 1038-1045.

3. Lord SE, McPherson K, McNaughton HK, Rochester L, Weatherall M (2004) Community ambulation after stroke: how important and obtainable is it and what measures appear predictive? Arch Phys Med Rehabil 85: 234-239.

4. Hill K, Ellis P, Bernhardt J, Maggs P, Hull S (1997) Balance and mobility outcomes for stroke patients: A comprehensive audit. Austral J Physiotherapy 43(3): 173-180.

5. Corrigan R, Mcburney H (2008) Community ambulation, Environmental impacts and assessment inadequacies. Disability and Rehabilitation 30(19): 1411-1419.

6. Haley SM, Langmuir L (2000) How do current post-acute functional assessments compare with the activity dimension of the International classification of functioning and disability (ICIDH-2)? J of rehabil measures 4(4): 51-56.

7. WHO (2001) International Classification of functioning, Disability and Health.
8. Keysor JJ, Jette AM, Coster W, Bettger JP, Haley SM (2006) Association of Environmental factors with levels of home and community participation in an adult rehabilitation cohort. Arch of phys med rehabil 87: 15661575 .

9. Whiteneck GG, Gerhart K A, Cusick CP (2004) Identifying environmental factors that influence the outcomes of people with traumatic brain injury. J head trauma rehabil 19(3): 191-204.

10. Whiteneck GG, Harrison- Felix CL, Mellick DC, Brooks CA, Charlifue SB, et al. (2005) Quantifying Environmental factors: a measure of physical, attitudinal service, productivity and policy Barriers. Arch of phys med rehabil 85: 1324-1335.

11. Wee J, Lysaght R (2009) Factors affecting measures of activities and participation in persons with mobility impairment in persons with mobility impairment. Arch of Phys med Rehabil 31(20): 1633-1642.

12. Rochette A, Desrosiers J, Noreau L (2001) Association between personal and environmental factors and the occurrence of handicap situations following a stroke. Disability and Rehabilitation 23(13): 559-569.

13. Robinson, Cynthia A (2010) Identifying personal factors associated with participation in community walking following stroke. Doctor of philosophy. University of Washington, USA.

14. Belanger L, Bolduc M, Noel M (1988) Relative importance of after-effects, environment and socio-economic factors on the social integration of stroke victims. Int. J. Rehab. Research 11(3): 251-260.

15. Rimmer JH, Wang E, Smith D (2008) Barriers associated with exercise and community access for individuals with stroke. Journal of rehabilitation research and development 45(2): 315-322.

16. Corrigan R, McBurney H (2008) Community ambulation: influences on therapists and clients reasoning and decision making. Disabil Rehabil 30: 1079-1087.

17. Pyoria $\mathrm{O}$, Talvitie U, Nyrkko H, Kautiainen $H$, Pohjolainen T. The effect of two physiotherapy approaches on physical and cognitive functions and independent coping at home in stroke rehabilitation. A preliminary follow-up study. Disabil Rehabil, 2007; 29: 503-511. 